\title{
Left-sided portal hypertension with a patent splenic vein: An impossible or a not-so-uncommon scenario?
}

\author{
Iftikhar Khan, Ghassan Ramahi, Saif Zaabi, Hussien Elsiesy, \\ Mansour Tawfeeq, Mohammed Al-Qahtani
}

\begin{abstract}
Introduction: Left-sided portal hypertension is usually thought to result from a mechanical obstruction of the splenic vein. However, a functional obstruction of a patent splenic vein due to high venous flow can also cause left-sided portal hypertension. Case Report: We report a case of left-sided portal hypertension with a patent splenic vein. Conclusion: The case illustrates that left-sided portal hypertension is a syndrome that results from the variable interactions of different mechanisms and highlights that the selection of suitable treatment is based on understanding the portal pathophysiology and portal venous anatomy in the patient.
\end{abstract}

Keywords: Left-sided portal hypertension, Management, Patent splenic vein, Pathogenesis

Iftikhar Khan ${ }^{1}$, Ghassan Ramahi ${ }^{1}$, Saif Zaabi ${ }^{2}$, Hussien Elsiesy $^{3}$, Mansour Tawfeeq ${ }^{1}$, Mohammed Al-Qahtani ${ }^{1}$

Affiliations: ${ }^{1}$ Transplant Surgeon, Department of Transplant Surgery, King Fahad Specialist Hospital, Dammam, Saudi Arabia; ${ }^{2}$ Interventional Radiologist, Department of Medical Imaging, King Fahad Specialist Hospital, Dammam, Saudi Arabia; ${ }^{3}$ Transplant Hepatologist, Department of Transplant Hepatology, King Fahad Specialist Hospital, Dammam, Saudi Arabia.

Corresponding Author: Dr. Iftikhar Khan, MOTC, KFSH, PO Box: 15215, MBC: 067, Dammam 31444, Saudi Arabia; Ph: +966-13-844-2474; Fax: +966-13-842-6251; Email: iftikhar. khan@kfsh.med.sa

Received: 02 September 2015

Accepted: 02 November 2015

Published: 07 December 2015

\section{How to cite this article}

Khan I, Ramahi G, Zaabi S, Elsiesy H, Tawfeeq M, Al-Qahtani M. Left-sided portal hypertension with a patent splenic vein: An impossible or a not-souncommon scenario? Int $J$ Hepatobiliary Pancreat Dis 2015;5:108-112.

Article ID: 100044IJHPDIK2015

$* * * * * * * *$

doi:10.5348/ijhpd-2015-44-CR-19

\section{INTRODUCTION}

Left-sided portal hypertension (LSPH) is clinically defined as a triad of bleeding from gastric fundal varices, normal liver function tests and splenomegaly [1]. There is a frequent association between LSPH and mechanical splenic vein obstruction (MSVO), which has been used to define and diagnose these cases [1-4]. In their topical reviews, Sutton et al. [3], who found 54 cases between 1900 and 1968, and Madsen et al. [4], who found 209 cases between 1969 and 1984, used isolated splenic vein thrombosis as the criterion for inclusion in their series of LSPH cases. However, LSPH can occur with a patent splenic vein [2]. We report one such case followed by a discussion about its pathogenesis and management.

\section{CASE REPORT}

An 18-year-old female with a biopsy-proven congenital hepatic fibrosis presented to us with hematemesis. This 
was her fourth episode of hematemesis from gastric fundal varices in the previous two months. The treatment was an endoscopic injection of $N$-butyl-2-cyanoacrylate (Histoacryl@, B. Braun Aesculap, Tuttlingen, Germany) mixed with Lipiodol (Lipiodol Ultra-Fluide $®$, Guerbet, Cedex, France) into the fundal varices in all four episodes. There were no esophageal varices. Her biochemical liver function tests were normal. Abdominal contrast enhanced magnetic resonance scan in the interim had shown splenomegaly, a patent splenic vein and a splenorenal shunt (Figure 1). To treat her recurrent bleeding, it was decided to create transjugular intrahepatic portosystemic shunt (TIPS). As the pre-TIPS measurement of hepatic venous pressure gradient (HVPG) was $5 \mathrm{mmHg}$, TIPS was deemed to be unsuccessful in controlling her bleeding; this also confirmed LSPH. Balloon-occluded retrograde transvenous obliteration (BRTO) of the fundal varices was attempted. Left renal venogram showed a spontaneous splenorenal shunt (Figure 2). As the diameter of the splenorenal shunt was large, it could not be managed because of technical reasons. Therefore,
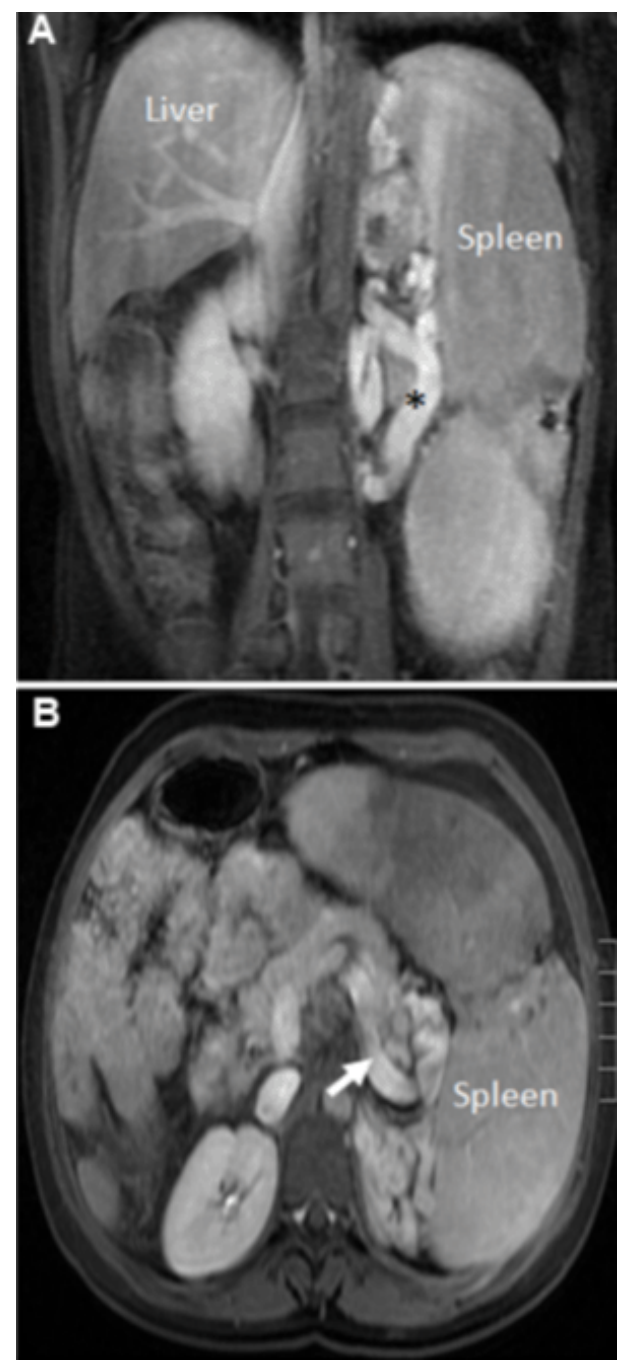

Figure 1: Portal venous anatomy. Coronal (A) and transverse (B) sections from a contrast-enhanced MR scan showing a splenorenal shunt $(*)$ and a patent splenic vein (arrow).

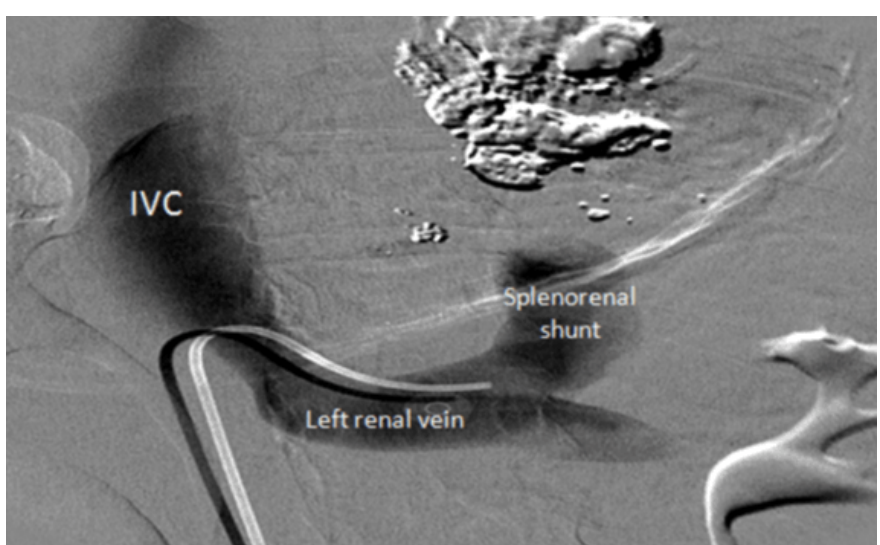

Figure 2: Left renal venogramshowing the splenorenal shunt. Abbreviation: IVC: inferior vena cava.

the BRTO was aborted. The patient was transferred to the operating room. The patent splenic vein was confirmed on laparotomy. She underwent a splenectomy, devascularization of the proximal greater curvature and a ligation of the coronary vein. Her spleen weighed $1123 \mathrm{~g}$. During the 40-month follow-up, she did not bleed further. Repeat endoscopy showed resolving fundal varices.

\section{DISCUSSION}

Natural history and clinical features of portal hypertension depend on its pathophysiology. The two main mechanisms that contribute to the development and maintenance of portal hypertension are increased resistance to portal blood flow (Backward flow theory) and an increased splanchnic blood flow (Forward flow theory) [5].These two mechanisms are influenced by molecular, cellular and mechanistic factors, yet the relative contribution of each factor in a given case remains undetermined. A particular mechanism operates dominantly in each clinical or experimental situation. In clinical practice, this variation may explain the variable success observed with a particular drug or operation. Like "micro" factors, there are "macro" factors that dictate the development of portal hypertension, the appearance of varices and the risk of bleeding. There are five macro factors influencing the development of LSPH:

(a) The anatomy of the portal venous system because the drainage of the left gastric vein into the splenic vein or the main portal vein determines whether esophageal varices would develop in a patient with MSVO who had developed gastric fundal varices [6].

(b) Splenomegaly results from the combination of congestion and hyperplasia [7], and, in some cases, may also be contributed to by the primary disease infiltration, which is usually hematological. Splenomegaly leads to increased splanchnic blood flow (the forward flow component). 
Once portal hypertension is established, the removal of the splenic venous compression alone without splenectomy may not resolve the portal hypertension [7] as portal hypertension is maintained by the persistent splenic hyperplasia.

(c) MSVO is not essential for the development of LSPH. A patent splenic vein becomes functionally obstructed as it is unable to accommodate the increased blood flow. A classic example is the compression of the patent splenic vein by a pancreatic tumor [2]. However, not all patients with MSVO develop gastric varices due to effective decompression through the collaterals [1].

(d) A spontaneous splenorenal shunt, connecting the splenic vein to the left renal vein, may effectively drain the "right side" of the portal system; the HVPG remains normal but still leads to LSPH and hematemesis [8].

(e) The majority of patients with MSVO develop venous collaterals from the spleen through the short gastric veins into coronary vein and splenorenal shunt. Alternate pathways, such as colonic collaterals, may develop. The development of alternate pathways is influenced by the previous surgical history and the distance between the splenic venous obstruction and the splenic hilum [9]. LSPH is the final result of the interaction of all of these factors (Figure 3).

In our patient, we hypothesize that increased resistance to the portal flow from congenital hepatic fibrosis led to congestive and hyperplastic splenomegaly with a consequent increased portal flow. The patent splenic vein was unable to accommodate the increased blood flow. The spontaneous splenorenal shunt developed and decompressed the right side but was ineffective in decompressing the left side and led to the fundal variceal bleeding. These events cannot be confirmed, but they represent a reasonable predicted course. As the splenectomy prevented further hematemesis, it shows that the forward flow component was the major mechanism contributing to the generation of the portal hypertension in this patient.

The true incidence of LSPH is undetermined because asymptomatic cases are not investigated and symptomatic cases may be misdiagnosed as generalized portal hypertension [1]. The occurrence of LSPH with a patent splenic vein is a less recognized but known entity. In a prospective study of 24 LSPH patients, 12 patients had total or partial patent splenic veins [2].

The LSPH should be suspected in patients with gastric fundal varices with normal liver function tests. Splenomegaly has been shown to be present in 50$70 \%$ of LSPH patients in a number of studies [2-4]. The choice and sequence of the investigations for LSPH depend on its clinical presentation, primary disease, resources, expertise and index of suspicion. Upper gastrointestinal endoscopy demonstrates isolated gastric fundal varices in over $90 \%$ of cases [1]. The portal anatomy, its collaterals and MSVO are determined by imaging modalities such as abdominal and endoscopic Doppler ultrasound and computed tomography and magnetic resonance angiography. Invasive modalities, such as visceral arteriogram with a portal venous phase, are used selectively $[1,6]$. The measurement of HVPG should be considered when planning for TIPS. If HVPG is $<12 \mathrm{mmHg}$, TIPS is not recommended [10]. A normal

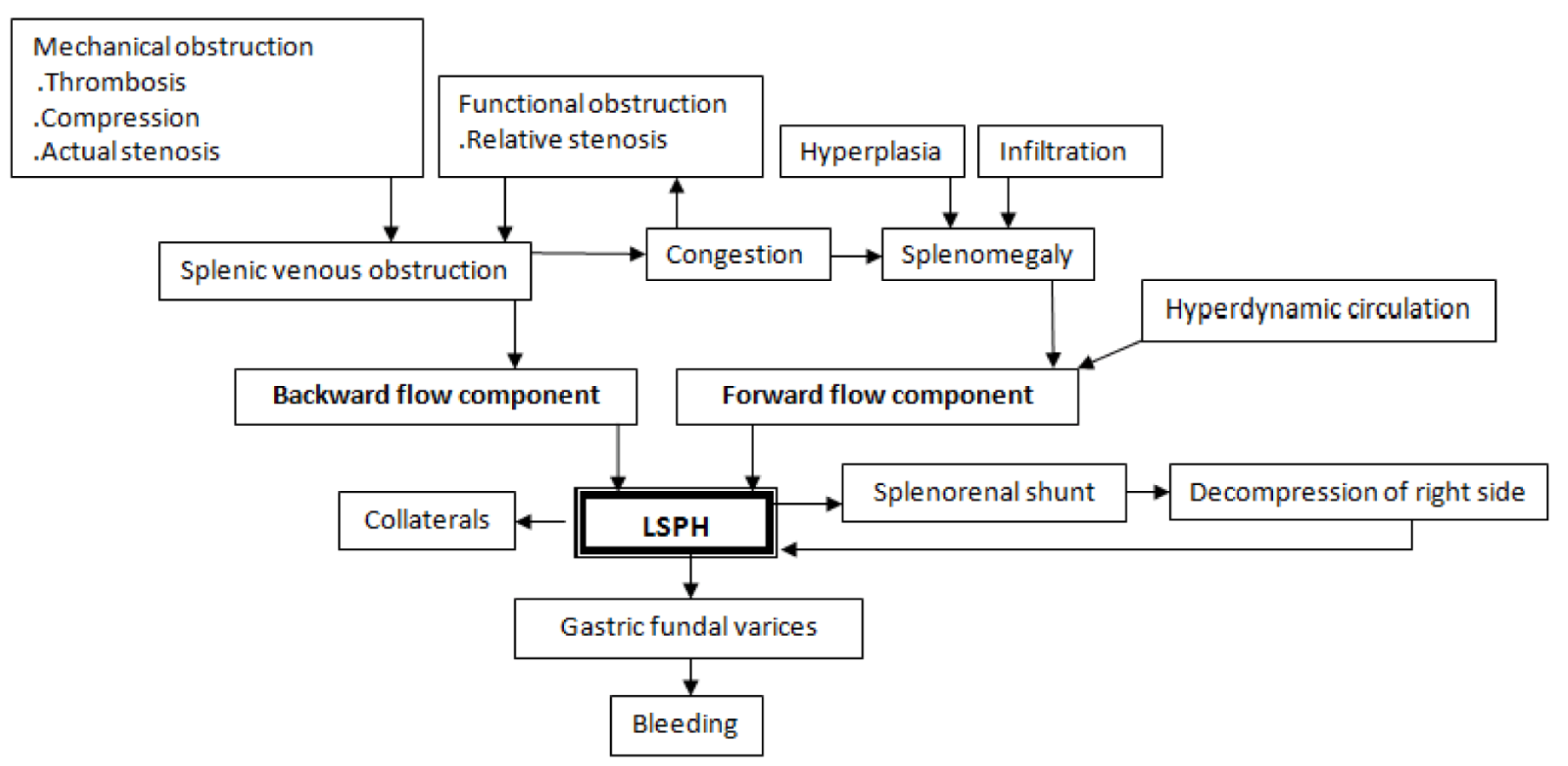

Figure 3: Pathophysiology of LSPH. 
HVPG with bleeding gastric varices confirms LSPH. A visualization of splenorenal shunt by left renal venogram is a prerequisite for BRTO [8].

Although there is no consensus regarding asymptomatic patients, given the low risk of bleeding in these patients with LSPH, they may be observed without intervention [1]. The availability of many treatment options for symptomatic patients mandates that the physician studies the pathogenic and anatomical factors so that the most appropriate modality is selected. The small number of patients and the invasive nature of the treatment modalities do not allow randomized controlled trials to be conducted. Endoscopic cyanoacrylate injection into the bleeding gastric varices at the time of diagnostic endoscopy is the standard initial treatment [8], and temporarily controls the bleeding. For permanent control, a splenectomy remains the treatment of choice for fit patients $[1,2]$ but there are other options. Patients with an elevated HVPG should be considered for TIPS [10]. Patients with a patent splenic vein and splenorenal shunt should be considered for BRTO [8]. Splenic arterial embolization is an option for unfit and frail patients [1].

\section{CONCLUSION}

In conclusion, left-sided portal hypertension (LSPH) is a syndrome resulting from a complex interaction of different mechanisms that are initiated by different diseases affecting the liver, portal circulation or spleen. Presently, while many options to treat LSPH are available, LSPH should be diagnosed at anatomical and pathophysiological levels so that the most appropriate treatment is selected for the patient.

$* * * * * * * * *$

\section{Author Contributions}

Iftikhar Khan - Substantial contributions to conception and design, Acquisition of data, Analysis and interpretation of data, Drafting the article, Revising it critically for important intellectual content, Final approval of the version to be published

Ghassan Ramahi - Acquisition of data, Analysis and interpretation of data, Drafting the article, Revising it critically for important intellectual content, Final approval of the version to be published

Saif Zaabi - Analysis and interpretation of data, Revising it critically for important intellectual content, Final approval of the version to be published

Hussien Elsiesy - Analysis and interpretation of data, Revising it critically for important intellectual content, Final approval of the version to be published

Mansour Tawfeeq - Analysis and interpretation of data, Revising it critically for important intellectual content, Final approval of the version to be published Mohammed Al-Qahtani - Analysis and interpretation of data, Revising it critically for important intellectual content, Final approval of the version to be published

\section{Guarantor}

The corresponding author is the guarantor of submission.

\section{Conflict of Interest}

Authors declare no conflict of interest.

\section{Copyright}

(C) 2015 Iftikhar Khan et al. This article is distributed under the terms of Creative Commons Attribution License which permits unrestricted use, distribution and reproduction in any medium provided the original author(s) and original publisher are properly credited. Please see the copyright policy on the journal website for more information.

\section{REFERENCES}

1. Köklü S, Coban S, Yüksel O, Arhan M. Left-sided portal hypertension. Dig Dis Sci 2007 May;52(5):1141-9.

2. Köklü S, Yüksel O, Arhan M, et al. Report of 24 left-sided portal hypertension cases: a singlecenter prospective cohort study. Dig Dis Sci 2005 May;5O(5):976-82.

3. Sutton JP, Yarborough DY, Richards JT. Isolated splenic vein occlusion. Review of literature and report of an additional case. Arch Surg 1970 May;100(5):623-6.

4. Madsen MS, Petersen TH, Sommer H. Segmental portal hypertension. Ann Surg 1986 Jul;204(1):72-7.

5. Benoit JN, Womack WA, Hernandez L, Granger DN. "Forward" and "backward" flow mechanisms of portal hypertension. Relative contributions in the rat model of portal vein stenosis. Gastroenterology 1985 Nov;89(5):1092-6.

6. Little AG, Moossa AR. Gastrointestinal hemorrhage from left-sided portal hypertension. An unappreciated complication of pancreatitis. Am J Surg 1981 Jan;141(1):153-8.

7. Bolognesi M, Merkel C, Sacerdoti D, Nava V, Gatta A. Role of spleen enlargement in cirrhosis with portal hypertension. Dig Liver Dis 2002 Feb;34(2):144-50.

8. Caldwell S. Gastric varices: Gastric varices: is there a role for endoscopic cyanoacrylates, or are we entering the BRTO era? Am J Gastroenterol 2012 Dec;107(12):1784-90.

9. Strasberg SM, Bhalla S, Sanchez LA, Linehan DC. Pattern of venous collateral development after splenic vein occlusion in an extended Whipple procedure : comparison with collateral vein pattern in cases of sinistral portal hypertension. J Gastrointest Surg 2011 Nov;15(11):2070-9.

10. Tripathi D, Therapondos G, Jackson E, Redhead DN, Hayes PC. The role of the transjugular intrahepatic portosystemic stent shunt (TIPSS) in the management of bleeding gastric varices: clinical and haemodynamic correlations. Gut 2002 Aug;51(2):270-4. 
Access full text article on other devices

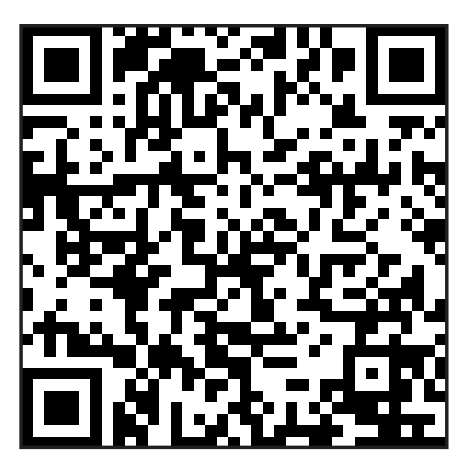

Access PDF of article on other devices

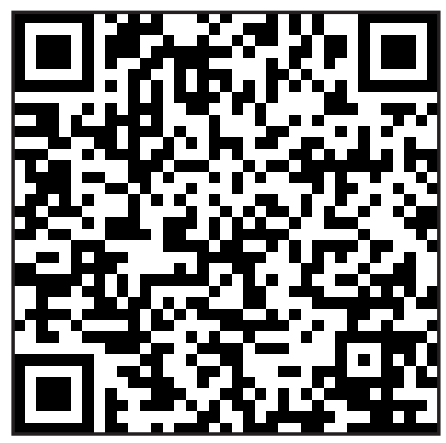

